\title{
AC 2011-1239: ENGINEERING FUTURE CHEMICAL ENGINEERS: IN- CORPORATION OF PROCESS INTENSIFICATION CONCEPTS INTO THE UNDERGRADUATE CURRICULUM
}

\author{
Rebecca K. Toghiani, Mississippi State University
}

Dr. Rebecca K. Toghiani is an Associate Professor of Chemical Engineering at MSU. She received her B.S.ChE, M.S.ChE and Ph.D in Chemical Engineering from the University of Missouri-Columbia. She received the 1996 Dow Outstanding New Faculty Award and the 2005 Outstanding Teaching Award from the ASEE Southeastern Section. A John Grisham Master Teacher at MSU, she is an inaugural member of the Bagley College of Engineering Academy of Distinguished Teachers. She has also been recognized at MSU with the 2001 Outstanding Faculty Woman Award, a 2001 Hearin Professor of Engineering award, and the 1999 College of Engineering Outstanding Engineering Educator Award.

\section{Adrienne R. Minerick, Michigan Technological University}

Adrienne Minerick is an Associate Professor of Chemical Engineering at Michigan Tech having moved from Mississippi State University in Jan 2010, where she was a tenured Associate Professor. She received her M.S. and Ph.D. from the University of Notre Dame in 2003 and B.S. from Michigan Technological University in 1998. Adrienne's research interests include electrokinetics and the development of biomedical microdevices. She earned a 2007 NSF CAREER award; her group has published in the Proceedings of the National Academy of Science, Lab on a Chip, and had an AIChE Journal cover. She is an active mentor of undergraduate researchers and served as co-PI on an NSF REU site. Research within her Medical micro-Device Engineering Research Laboratory (M.D. ERL) also inspires the development of Desktop Experiment Modules (DEMos) for use in chemical engineering classrooms or as outreach activities in area schools. Adrienne has been an active member of ASEE's WIED, ChED, and NEE leadership teams since 2003.

\section{Keisha B. Walters, Mississippi State University}

Keisha B. Walters is an Assistant Professor of Chemical Engineering at Mississippi State University (MSU). She received her B.S. degree in Biological Sciences from Clemson University in 1996 and her M.S. and Ph.D. degrees in Chemical Engineering from Clemson University in 2001 and 2005. Dr. Walters has taught core courses at the undergraduate (Fluids, Heat Transfer, Transport Phenomena) and graduate levels (Transport Phenomena, Kinetics and Reactor Design). She also (co)teaches elective courses in Polymeric and Multicomponent Materials and Experimental Methods in Materials Research. Dr. Walters is an inducted member of the MSU Bagley College of Engineering Academy of Distinguished Teachers and has been a member of ASEE since 2002.

\section{Priscilla J Hill, Mississippi State University}

Priscilla J. Hill is currently an Associate Professor at Mississippi State University. Her research interests include solids processing, crystallization, and particle technology. She received her B.S. and M.S. degrees from Clemson University and her Ph.D. degree from the University of Massachusetts at Amherst. She has taught design, thermodynamics, and mass transfer courses at the undergraduate level; a graduate course on thermodynamics; and a split level elective course on particle and crystallization technology.

\section{Carlen Henington, Mississippi State University}

Dr. Carlen Henington is a nationally certified School Psychologist and is an associate professor in School Psychology at Mississippi State University. She completed her doctoral work at Texas A\&M University and her internship at the Monroe Meyer Institute for Genetics and Rehabilitation at the University of Nebraska Medical Center, Omaha. She received the Texas A\&M Educational Psychology Distinguished Dissertation Award in 1997, the Mississippi State University Golden Key National Honor Society Outstanding Faculty Member Award in 2000, and the Mississippi State University Phi Delta Kappa Outstanding Teaching Award in 1998. She has worked as a consultant to Mississippi Department of Education (MDE) to address disproportionality and has provided technical assistance to schools across the state. She has assisted with MDE on monitoring visits and has presented nationally on effective academic and behavioral interventions with children in the schools. 


\title{
Engineering Future Chemical Engineers: Incorporation of Process Intensification Concepts into the Undergraduate Curriculum. Year 2
}

\begin{abstract}
Process intensification encompasses a broad spectrum of activities focused on identifying fundamental limitations in a chemical production route, and developing or combining processes to minimize resource utilization and optimize product quality. Process intensification is essential to industrial competitiveness as it can enhance safety, increase operating efficiency, lower energy usage, reduce capital costs, reduce waste emissions and process hazards, or encompass several of these benefits. Improving processes by process intensification requires engineers to integrate many fundamental concepts and go beyond traditional unit operations. Currently, most chemical engineers are trained in fundamentals using a unit operations approach where the material is subdivided between courses. Engineers are often taught how to synthesize a process by linking together standard unit operations, but are frequently not trained to combine/exploit fundamental concepts in new ways for novel and efficient process designs. This project seeks to correct this deficiency through the development of process intensification instructional modules for use in existing courses.
\end{abstract}

Four core chemical engineering courses are targeted: fluid flow operations; heat transfer operations; mass transfer operations; and chemical reactor design. Over the three-year CCLI project, activities/modules will be developed and incorporated into each of these courses, with each activity/module focusing on a particular element from the process intensification spectrum and designed to also enhance vertical concept integration. This poster presentation focuses on the activities and modules developed in Year 2. The preliminary assessment data collected from Year 1 implementation are also presented.

\section{Introduction}

The chemical industry faces numerous challenges in the coming years due to decreasing availability of raw material and energy resources. Thus, existing processes must operate in an efficient manner, with maximum yield of products from a fixed feedstock. Development and design of new chemical processes requires chemical engineers to sequence production steps to accomplish the necessary transformative steps taking the feed material and converting it into a product or products with acceptable market value. The manner in which the conversion is accomplished can vary from company to company; however, the traditional approach has been to sequence single purpose unit operations to accomplish the conversion. This has been a very successful strategy in the past, and has been the structure for instruction of chemical engineering design education.

In recent years, a paradigm has begun to emerge in the industry, whereby two or more steps in the production sequence are combined to yield a more energy efficient or more environmentally friendly process to accomplish multiple steps simultaneously. The reduced energy footprint is 
often accompanied by a decrease in capital cost, as these multiple steps are accomplished in a single piece of equipment.

The need to align chemical engineering design education with this new paradigm is essential for the U.S. chemical industry to remain competitive in the coming decades. However, the premise of the project investigators is that process intensification education and activities cannot simply be considered in the final stages of design, and not only in an upper level elective course, but must permeate throughout the undergraduate chemical engineering curriculum. Thus, instructional materials are being developed for a sequence of four core chemical engineering undergraduate courses. Typically, these courses are taken prior to the student enrolling in the senior design course (or courses). The four core courses that are targeted are: 1) fluid flow operations; 2) heat transfer operations; 3) mass transfer operations; and 4) reactor design. The first three of these courses are typically grouped as the 'unit operations' courses. The last course may be taken prior to the senior year design courses, or during the first semester of the senior year simultaneously with the first course in the design sequence.

\section{Process Intensification}

Process intensification was identified by the NSF as early as 1993 as a specific area in which research endeavors should be concentrated to meet the needs of the chemical industry; ${ }^{1}$ almost one hundred archival articles were published on process intensification topics in $2008 .^{2}$ The number of such articles identified using the term "process intensification' in SciFinder Scholar in 2009 and 2010 are 103 and 95, respectively.

Benefits of process intensification activities include: ${ }^{3,4}$ 1) novel or enhanced products; 2) improved chemistry; 3) enhanced safety; 4) improved processing; 5) energy and environmental benefits; 6) capital cost reduction; and 7) low inventories. Key to the endeavor is an ability to identify the limitation(s) in a process, and knowledge of mechanisms that may be employed to eliminate them. One of the barriers identified by Tsouris and Porcelli ${ }^{3,4}$ as well as Stankiewicz and Moulijn ${ }^{5}$ is the sequential, unit operations-oriented approach typically used in undergraduate chemical engineering education. Much of the activity in the process intensification area has been in the European community. ${ }^{4}$ The University of Newcastle on Tyne in the UK has established a graduate curriculum in chemical engineering focused on "intensified processing." 6 Recently, it has been suggested that ChE Ed should include aspects of integrated concepts at the undergraduate level. ${ }^{7,8}$ Also posed by these proponents is the question "Should ChE Ed include new disciplines such as ... process intensification and miniaturization technology?” In the United States, the process intensification discussion is still primarily conducted in industry and by academic research teams; ${ }^{4}$ to the knowledge of the project team, incorporation of process intensification at the undergraduate level has not been explored to date.

The incorporation of process intensification across the curriculum requires a critical examination of traditional topics currently taught in each course, and identification of appropriate topics that may allow expansion of existing instruction to concepts directly related to the tenants of process intensification. Integration of concepts from one course to subsequent courses is also an essential component of this incorporation process. The ability of students to successfully perform this integration has been a recent interest of the project team. ${ }^{9}$ Further, it is believed that 
the development of process intensification modules would significantly impact academia and the diverse industries relying on chemical engineers because students trained to be versatile thinkers are more likely to conceive novel, more efficient production routes leading to innovative processes with respect to energy and material efficiencies.

\section{U.S. Educational Needs}

Chemical engineering departments in the U.S. cannot afford to be complacent about ChE Ed given the need for global competitiveness. A CCR/NSF Discipline Wide Curriculum Workshops panel was convened to determine what chemical engineering curricular changes are necessary to keep the U.S. competitive. ${ }^{10}$ The panel concluded that "the curriculum should integrate all organizing principles and basic supportive sciences throughout the educational sequence”, that "all organizing principles should be operative in the curriculum throughout the sequence", and that "the curriculum should be consistently infused with relevant and demonstrative laboratory experiences." There is a critical need for chemical engineers to be conversant in synthesizing and optimizing unit operations; this project aims to address these needs using novel process intensification modules. The new process intensification examples require the integration of concepts across four core courses, reinforce these concepts throughout the curriculum, and provide examples of how the combination of basic principles from different unit processes are required to solve real problems.

\section{Project Activities}

An over-arching structure to the development of instructional modules has been developed. A minimum of three modules for each of the four core courses are being developed over the three year project, with one new module incorporated into each course each year of the project. For Year 2, these modules focused on Mixing (Fluid Flow Operations), Heat Transfer with Oscillatory Flow (Heat Transfer Operations), Column Internals/Configuration (Mass Transfer Operations), and Simulated Moving Bed Reactor Technology (Chemical Reactor Design).

The instructional materials in development focus on concepts critical to process intensification, with an emphasis on both cross-fertilization and vertical integration. For example, in year 1, instructional materials for the mass transfer operations course focused reactive distillation, an intensified process where reaction and separation are carried out simultaneously in an integrated reactor/column. To build on this coupling of separation and reaction, year 2 instructional materials for the reactor design course focus on SMBR technology (simulated moving bed reactor), which combines reaction with adsorption. Thus, the concept of coupling reaction and separation is reinforced through these activities.

\section{Year 2 Activities}

\section{Fluid Flow Operations}

Specific objectives of this educational module are: 1) understanding of the importance of fluid transport in passive and active mixing; 2) examination of the dependence of flow profiles on

mixing mechanisms and Reynolds number regime; and 3) relating the impact of mixing to 
enhancements possible in heat transfer, mass transfer/separations and reactions. Examples employed to demonstrate these concepts through instructional materials include examination of the impact of roughened/machined surfaces, the presence of baffles, and oscillatory flow. A discussion of the static mixer-reactor connects the concepts examined in the module to the reactor design course. Flow through a smooth tube is examined and compared with flow through the same tube after the addition of a spring/coil insert and baffles. Oscillatory flow is also examined in these tube configurations.

\section{Heat Transfer Operations}

Heat Transfer Operations is taught only in the spring semester during the academic year. For Year 1, a module was developed focused on conduction/heat transfer in microdevices and through thin films. In general, heat conduction in small volumes was stressed as an important topic because small fluid volume systems will become more prevalent in process intensification as more is done with less volume and in new geometries. Typical applications of these fundamental phenomena are found in microdevices and microreactors such as the intensified absorption cycle air conditioner, ${ }^{11,12}$ spinning disc reactor, ${ }^{13}$ fuel cells where heat transfer in thin films is exploited, ${ }^{14}$ or falling film microreactors (FFMR). ${ }^{15}$ The module topic was reforming of hydrocarbon fuels in a portable microreactor to produce hydrogen gas [adapted from reference 15]. Students were walked through the physics of the problem to develop a model including convection in the thin fluid layer on either side of the channel, reactions within this film and conduction through the walls in both the cross and axial directions. An energy balance was built for the system and developed by tying into the student's thermodynamics knowledge. From reference [15], the module covered three interesting cases for which the system could be operated.

i. "Heat transfer between two nonreacting fluids (microscale heat exchanger).

ii. Heat transfer between one exothermically reacting fluid and one nonreacting fluid (microscale regenerative combustion), and

iii. Heat transfer between one exothermic reacting fluid and one endothermic reacting fluid (microscale heat exchanger reactor)."

The students simplified the governing energy balance and drew diagrams showing the physics in groups of 2 to 3 for each of these cases. A homework exercise asked them to do further reading on examples from industry.

During Year 2, the focus of module development is on heat transfer with oscillatory flow. Convective heat transfer is extensively examined in the course, with exposure of students to both forced and natural convection. Natural convection is more energy efficient and so process intensification efforts build on this efficiency through use of creative and novel designs, environment, or fluids. Heat transfer fluids exhibit variable properties and are used in very diverse chemical engineering applications. These fluids, while isolated from process streams, often function under dynamic conditions. In these situations, it is necessary to know and to monitor fluid behavior as a function of flow rate, inlet and outlet temperatures and pressures. ${ }^{16}$ Oscillatory flow shows potential in process intensification because smaller volumes of high heat capacity fluids are utilized to transfer the same amount of energy as continuous cooling water 
exchangers. For a fluid operating under these varying conditions, the dynamic nature of the process on the properties of the fluid is studied. Class lecture materials and an in-class problem are enhanced with COMSOL Multiphysics ${ }^{\circledR}$ simulations that visually show the heat transfer and can compare to single pass methods. The existing content in the heat transfer course is being modified to address these simultaneous considerations.

\section{Mass Transfer Operations}

Mass Transfer Operations is currently taught only in the spring semester each academic year. For Year 1, a reactive distillation module was developed for the mass transfer course in the context of reactive distillation being an example of process intensification. This was adapted from various sources. ${ }^{17-19}$ Previous lectures in the class discussed distillation fundamentals and techniques used to split azeotropes. The production of methyl acetate by reactive distillation was presented. This included a comparison was made between the conventional process that used 8 distillation columns and had a conversion of approximately $30 \%$ in the reactor, and the reactive distillation process than can ideally be performed in one equipment unit at higher conversion. The need for the 8 columns in the traditional process is largely due to the two minimum boiling point azeotropes methanol/methyl acetate and water/methyl acetate. Design differences and considerations between the two processes were discussed. Although the students had not taken the reactor design course, they had learned about stoichiometry and reversible reactions in prerequisite courses. Therefore, the benefits for removing products from a reversible reaction to drive the reaction in the desired direction were explained. Process intensification was integrated into the presentation by emphasizing the energy savings due to reducing the number of distillation columns, the cost savings due to fewer equipment units and lower energy costs, and the improved material efficiency.

Since the students had not yet taken the reactor design/kinetics course in the curriculum, they were not able to set up reactive distillation in a process simulator. However, ChemCAD has an example of reactive distillation where ethyl acetate is produced from acetic acid and ethanol. The students can perform sensitivity studies on the existing example.

Year 2 activities in Mass Transfer Operations focus on column internals and column configuration. Column design is typically focused on determination of number of equilibrium stages and estimation of column diameter for either tray columns or packed columns. Packed columns examined in the course have historically been those utilizing random packings.

Instructional content covering structured packing and thermal coupling will be incorporated. A new approach to structured packing design reduces pressure drops by redistributing gas and liquid flows. This approach can significantly increase column capacity as described in a series of papers. $^{20-22}$ However, this process intensification concept is not typically introduced in mass transfer courses. An instructional module will be developed to introduce students to these concepts and will consist of teaching materials, homework exercises and test questions.

One class example of thermally coupled columns is the Petyluk column configuration. ${ }^{23}$ Thermal coupling can also be accomplished in a single distillation tower shell, where a vertical wall is introduced, effectively dividing the column into the prefractionator and the main column. 
The divided wall column configuration is advantageous in that it has the potential to provide higher thermodynamic efficiency than for sequential columns performing the same separations for a ternary system. ${ }^{24}$ An overview of this configuration is given by Schultz et al. ${ }^{25}$ with more detail provided by other researchers. ${ }^{26-27}$ The teaching module will include instructional material as well as new ChemCAD examples for thermally coupled columns.

\section{Chemical Reactor Design}

An instructional module focused on simulated moving bed reactor (SMBR) technology was developed and incorporated into the Chemical Reactor Design course. This course, taken by first semester seniors, is the first exposure to chemical kinetics and reactor design. The text employed in the course Elements of Chemical Reaction Engineering by Fogler ${ }^{28}$ provides a sound introduction to the important concepts of chemical reactor design. Additionally, text material also provides instruction in a number of novel reactor configurations including membrane reactors, chemical vapor deposition reactors, and reactive distillation. Available on the website developed by Fogler are instructional modules that are used to supplement student learning on the topics of membrane reactors and reactive distillation. ${ }^{29}$ These existing modules were used as instructional assignments to provide exposure to coupling of separation and reaction using membranes and reactive distillation.

The simulated moving bed reactor exemplifies process intensification through the coupling of reaction and separation. The separation process is adsorption, with separation accomplished using a solid phase adsorbent that has an affinity for one or more reaction products. As the reaction proceeds in the SMBR, product(s) are removed from the reaction phase, and in the case of an equilibrium-limited reaction, this allows the reaction to proceed and achieve greater conversion. Simulated moving bed technology for separation has been commercially successful, with UOP introducing the technology in the 1960s. ${ }^{30}$ Its use coupling reaction with separation is relatively recent. ${ }^{31-33}$ The module is structured to provide instruction on a number of topics, including: 1) a review of adsorption as a separation process; 2) an introduction to moving bed technology and simulated moving bed technology, including basic configuration as well as advantages and disadvantages; 3 ) an overview of coupling of separation and reaction, with emphasis on equilibrium limited reactions; 4) an introduction to simulated moving bed reactor technology, including basic configuration and operation, constraints and limitations, and important process variables; and 5) industrial applications of simulated moving bed reactor technology. Integrated quizzes are included for each topic to provide feedback to students and assessment of student learning.

\section{Assessment}

Assessment results for Year 1 and for courses taught in Fall of Year 2 are discussed; all referenced tables are positioned at the end of this document. Ratings of students across 14 variables (Table 1) in Heat Transfer Operations and Chemical Reactor Design class early in the semester (Pre) and at the end of the semester (Post) used a survey that consisted of ratings of 0 (Disagree), 1 (Somewhat Agree), 2 (Somewhat Agree), and 3 (Agree). Table 1 provides the means at Pre and Post and the degree of change across rating times. 
At Pre intervention, all students in Heat Transfer Operations $(n=39 ; M=1.35$, scale 0 - 3 with 3 indicating higher ratings), Chemical Reactor Design ( $n=49 ; M=2.15$, scale 0 - 3), and Fluid Flow Operations ( $n=39 ; M=1.70)$ rated the Use of Activities at relatively lower levels. Additionally, at Pre intervention students in Heat Transfer Operations rated Encouraged to Use Flexibility $(M=1.56)$ at low levels with increased average ratings at Post $(M=2.47,(\Delta=0.91)$. Students' perceptions of the Use of Activities showed a significant increase in average ratings $(\Delta$ $=1.18)$ from Pre to Post $(M=2.53)$ the Heat Transfer Operations course. This was the greatest change in students' perception in both courses. Students in perceived minimal changes across all variables in the Chemical Reactor Design and Mass Transfer courses, with some variables slightly lower at then completion of the course relative to ratings at the beginning of the course.

For 43 participants in Fluid Flow Operations, data were able to be matched. A paired samples t test showed significance $t(1,42)=4.65, p<.000$ with ratings at Pre intervention significantly greater $(M=2.56, S D=1.81)$ higher than at Post $(M=1.81, S D=0.93)$ for students' perception of the ease of materials presentation. Additionally, a paired samples t test showed significance $\mathrm{t}(1,42)=2.96, p=.005$ with ratings at Pre intervention significantly higher $(M=1.98, S D=$ $0.83)$ than at Post $(M=1.51, S D=0.76)$ for students' perception that the activities furthered their understanding. See Table 2.

Data were matched (depending upon variable) for 30 to 34 participants in Heat Transfer Operations, a paired samples t test showed significance for several variables Pre to Post intervention (i.e., Used Activities, Furthered Understanding, Encouraged to Use Analysis, Can Use Analysis, Can Be Flexible). See Table 3. First, a significant difference was found for Used Activities to Illustrate concepts, $\mathrm{t}(1,33)=-9.16, p<0.000$ with ratings at Pre intervention significantly lower $(M=1.24, S D=0.78)$ than at Post $(M=2.56, S D=0.50)$. Second, a significant difference was found for Furthered Understanding, $\mathrm{t}(1,33)=-4.83, p<0.000$ with ratings at Pre intervention significantly lower $(M=1.58, S D=1.03)$ than at Post $(M=2.52, S D=$ 0.67). Third, a significant difference was found for Encouraged to Use Analysis, $\mathrm{t}(1,29)=-4.83$, $p<0.000$ with ratings at Pre intervention significantly lower $(M=4.17, S D=1.39)$ than at Post $(M=4.87, S D=1.33)$. Fourth, a significant difference was found for Can Use Analysis, $\mathrm{t}(1,32)=$ -2.25, $p<0.032$ with ratings at Pre intervention significantly lower $(M=1.94, S D=0.90)$ than at Post $(M=2.30, S D=0.68)$. Finally, a significant difference was found for Can Be Flexible, $\mathrm{t}(1,32)=-2.86, p<0.007$ with ratings at Pre intervention significantly lower $(M=1.97, S D=$ $0.63)$ than at Post $(M=2.35, S D=0.69)$.

Data were matched (depending upon variable) for 33 to 35 participants in Mass Transfer Operations, a paired samples $t$ test showed significance showed only significant for Can Use Analysis, $t(1,32)=2.82, \mathrm{p}=0.008$ with ratings at pre intervention significantly higher $(M=2.52$, $S D=0.91)$ than at post $(M=2.09, S D=0.72)$.

Data were matched (depending upon variable) for 36 to 37 students Pre to Post Intervention. No differences were found between students' perception, Pre to Post, on the 13 variables (Can Use Analysis was not assessed for students without intensification) within Chemical Reactor Design. In each case, ratings were higher without intensification with the exception of Encouraged to Integrate Materials/Knowledge and Can Use Synthesis. See Table 4. 
A comparison of perceptions of students with $(n=40)$ and without $(n=33)$ the process intensification activities in Chemical Reactor Design was computed using an independent samples $t$ test. Three of 13 variables (Can Use Analysis was not assessed for students without intensification) were found to have significant differences (i.e., Easily Presented, Used Activities to Illustrate, Can be Flexible. See Table 5.

During the Fall 2010 Chemical Reactor Design course, an integration activity was presented to students $(n=49)$ and an evaluation of knowledge was administered pre and post activity. The responses were grouped according to a single correct response on three questions (score right or wrong; e.g., range 0 to 3 ) and a multiple-choice question (scored 1 for each correct selection, e.g., 0 to 3). A paired sample t test was calculated to determine differences pre to post. Students scored significantly better, $\mathrm{t}(48)=-8.01, p<0.000$ and $\mathrm{t}(48)=-12.95, p<0.000$, respectively, on the post lecture than they did at pre lecture. See Table 6 for mean scores.

Integrity checks with class activities conducted two times during the semester in both courses indicated instructors were rated at relatively high levels across all variables (inter observer agreement at $92 \%)$.

\section{Summary}

Integration of key concepts related to process intensification across multiple core chemical engineering courses provides the opportunity for students to become both familiar with the tenets of process intensification as well as be equipped to examine intensified process alternatives during the senior design courses. As students progress through the four-course sequence, it is expected that their foundation will become stronger in these tenets and they will be better equipped to face the challenges that will be present when they graduate and enter the chemical engineering workforce.

\section{Acknowledgement}

This work is funded through the National Science Foundation Course, Curricula and Laboratory Improvement (CCLI) program under grant DUE-0837409.

\section{Bibliography}

1. McGee, H.A., Jr.; Burka, M.K.; Editors. Opportunities in Manufacturing Research in the Process Industries. Report NSF 93-69 (1993).

2. Web of Science Database search for "Process Intensification yielded $~ 80$ archival journal articles published in 2008. Accessed 5/19/2008.

3. Tsouris, C.; Porcelli, J.V. Process Intensification - Has Its Time Finally Come? Chem. Engr. Prog., 99(10): 50-55 (2003).

4. Tsouris, C.; Porcelli, J.V. Process Intensification - Has Its Time Finally Come? Report on Topical Conference and Workshop, AIChE, (2003a).

5. Stankiewicz, A.I.; Moulijn, J.A. Process Intensification: Transforming Chemical Engineering. Chem. Engr. Prog., 96(1), 22-34, (2000). 
6. $\quad$ (http://www.ncl.ac.uk/ceam/undergrad/degrees/index.htm

7. de Azevedo, S.F. Towards the European Higher Education Area: Curricula and Methods in Chemical Engineering, Keynote Lecture, Proceedings of European Congress of Chemical Engineering (ECCE-6), Copenhagen, 16-20 September 2007.

8. Charpentier, J.-C. "In the frame of globalization and sustainability, process intensification, a path to the future of chemical and process engineering (molecules into money)", Chem. Eng. J., 134, 84-92 (2007).

9. Toghiani, R.K., Minerick, A.R., Walters, K.B., "Making the Connections: Facilitating Student Integration of Chemical Engineering Concepts into a Coherent Framework," 2008 ASEE Conference Proceedings.

10. CCR/NSF Discipline Wide Curriculum Workshops, "Frontiers in Chemical Engineering Education: Overview Presentation of Frontiers Initiative”, http://web.mit.edu/checurriculum/statements/RCA_NSF_ChE_Frontiers_Overview.pdf, 19 May 2008.

11. Akay, G.; Mackley, M.R.; Ramshaw, C.; "Process Intensification: Opportunities for Process and Product Innovation” IChemE, 597-606, (1997).

12. Ramshaw, C and T. Winnington, “An intensified absorption heat pump.” Proc. Inst. Refrig, 85, 26-33, (1988).

13. Oxley, P.; Brechtelsbauer, C.; Ricard, F.; Lewis, N.; Ramshaw, C.; “Evaluation of Spinning Disk Reactor Technology for the Manufacture of Pharmaceuticals”, Ind. Eng. Chem. Res. 39, 2175-2182, (2000).

14. Kaisare, N.S., G.D. Stefanidis, and D.G. Vlachos, "Millisecond Production of Hydrogen from Alternative, High Hydrogran Density Fuels in a Cocurrent Multifunctional Microreactor,” Ind. Eng. Chem. Res., $\underline{48}$, 1749-1760, (2009).

15. Zhang, H. G. Chen, J. Yue, and Q. Yuan, "Hydrodynamics and Mass Transfer of Gas-Liquid Flow in a Falling Film Microreactor.” AIChE Journal, 55(5), 1110-1120, (2009).

16. Morena, A., K. Murphy, and B.A. Wilhite, "Parametric Study of Solid-Phase Axial Heat Conduction in Thermally Integrated Microchannel Networks,” Ind. Eng. Chem. Res., 47, 9040-9054, (2008).

17. Arseneault, G.; "Safe Handling of Heat Transfer Fluids,"Chem. Engr. Prog., 104(3), 42-47, (2008).

18. Wankat, P. C. Separation Process Engineering, 2nd ed., Prentice Hall: Upper Saddle River, 2007.

19. Doherty, M. F.; Malone, M.F. Conceptual Design of Distillation Systems, McGraw-Hill: Boston, 2001.

20. Stankiewicz, A. "Reactive separations for process intensification: an industrial perspective," Chemical Engineering and Processing, 42, 137-144 (2003).

21. Olujic, A.; Jansen, H.; Kaibel, B.; Rietfort, T.; Zich, E.; "Stretching the capacity of structured packings," Ind. Eng. Chem. Res., 40, 6172-6180, (2001).

22. Olujic, A.; Jansen, H.; Kaibel, B.; Rietfort, T.; Zich, E.; Frey, G.; "Distillation column internals/configurations for process intensification," Chem. Biochem. Eng. Quarterly, 17, 301-309, (2003).

23. Petyluk, F.B.; Platonov, V.M.; Slavinskii, D.M.; "Thermodynamically optimal method for separating multicomponent mixtures," Int. Chem. Engr., 5 , 555-561, (1965).

24. Mueller, I.; Kenig, E.Y.; "Reactive Distillation in a Dividing Wall Column: Rate-Based Modeling and Simulation," Ind. Eng. Chem. Res., 46, 3709-3719, (2007).

25. Schultz, M.A.; Stewart, D.G.; Harris, J.M.; Rosenblum, S.P.; Shakur, M.S.; O'Brien, D.E.; "Reduce Costs with Dividing Wall Columns," Chem. Eng. Prog., 64-71, May 2002.

26. Nikolaides, I.P.; Malone, M.M.; "Approximate Design and Optimization of a Thermally Coupled Distillation Column with Prefractionation," Ind. Eng. Chem. Res., 27, 811-818, (1988).

27. Agrawal, R.; Fidkowski, A.T.; "New Thermally Coupled Schemes for Ternary Distillation,” AIChE J., 45 , 485-496, (1999).

28. Fogler, H.S.; Elements of Chemical Reaction Engineering, Prentice-Hall, 4th edition, (2005).

29. Fogler, H.S.; <http://www.engin.umich.edu/ cre/>

30. UOP, "Making MTBE, ETBE, DIPE, TAME from Light Olefins for Gasoline Blending," $<$ http://www.uop.com/refining/1053.html>

31. Lode, F.; Mazzotti, M.; Morbidelli, M.; "A New Reaction-Separation Unit: The Simulated Moving Bed Reactor," Chimia, 55, 883-886, (2001).

32. Zhang, Z.; Hidajat, K.; Ray, A.K.; "Application of Simulated Countercurrent Moving-Bed Chromatographic Reactor for MTBE Synthesis," Ind. Eng. Chem. Res., 40, 5305-5316, (2001).

33. Ching, C.B.; Lu, Z.P.; "Simulated Moving-Bed Reactor: Applications in Bioreactions and Separation," Ind. Eng. Chem. Res., 36, 152-159, (1997). 
Table 1 Change $(\Delta)$ Pre to Post in Students Perceptions Pre to Post in Heat Transfer Operations ( $n=39)$, Fluid Flow Operations $(n=39)$, Chemical Reactor Design $(n=49)$, and Mass Transfer Operations $(n=33)$

\begin{tabular}{|c|c|c|c|c|c|c|c|c|c|c|c|c|}
\hline \multirow[b]{2}{*}{ Variable } & \multicolumn{3}{|c|}{$\begin{array}{c}\text { Heat Transfer } \\
\text { Operations }\end{array}$} & \multicolumn{3}{|c|}{$\begin{array}{c}\text { Chemical Reactor } \\
\text { Design }\end{array}$} & \multicolumn{3}{|c|}{$\begin{array}{l}\text { Fluid Flow } \\
\text { Operations } \\
\end{array}$} & \multicolumn{3}{|c|}{$\begin{array}{c}\text { Mass Transfer } \\
\text { Operations }\end{array}$} \\
\hline & Pre & Post & $\Delta$ & Pre & Post & $\Delta$ & Pre & Post & $\Delta$ & Pre & Post & $\Delta$ \\
\hline Easily Presented & 1.94 & 1.93 & -0.01 & 2.81 & 2.84 & 0.03 & 2.59 & 1.84 & -0.75 & 2.51 & 2.34 & -0.17 \\
\hline $\begin{array}{l}\text { Used Activities to } \\
\text { Illustrate }\end{array}$ & 1.35 & 2.53 & 1.18 & 2.15 & 2.08 & -0.07 & 1.70 & 1.61 & -0.09 & 1.68 & 1.47 & -0.21 \\
\hline $\begin{array}{l}\text { Encouraged to Use } \\
\text { Flexibility }\end{array}$ & 1.56 & 2.47 & 0.91 & 2.38 & 2.34 & -0.04 & 2.40 & 2.20 & -0.45 & 2.40 & 2.20 & -0.20 \\
\hline Furthered Understanding & 2.17 & 2.37 & 0.2 & 2.61 & 2.59 & -0.02 & 2.33 & 2.31 & -0.02 & 2.06 & 1.94 & -0.12 \\
\hline Can Problem Solve & 2.37 & 2.60 & 0.23 & 2.65 & 2.82 & 0.17 & 2.28 & 2.31 & 0.03 & 2.60 & 2.40 & -0.20 \\
\hline Can be Flexible & 2.39 & 2.60 & 0.21 & 2.65 & 2.82 & 0.17 & 2.28 & 2.31 & 0.03 & 2.35 & 2.41 & 0.06 \\
\hline $\begin{array}{l}\text { Encouraged to Integrate } \\
\text { Materials/ } \\
\text { Knowledge }\end{array}$ & 2.18 & 2.40 & 0.22 & 2.71 & 2.60 & -0.11 & 2.41 & 2.35 & -0.06 & 2.29 & 2.06 & -0.23 \\
\hline $\begin{array}{l}\text { Encouraged to Use } \\
\text { Analysis }\end{array}$ & $4.10^{*}$ & $4.85 *$ & 0.75 & $4.96 *$ & $5.05 *$ & 0.09 & 4.37 & 4.10 & -0.27 & 4.06 & 3.82 & -0.24 \\
\hline Can Use Analysis & 2.12 & 2.39 & 0.27 & 2.63 & 2.59 & -0.04 & 2.24 & 2.02 & -0.22 & 2.52 & 2.09 & -0.43 \\
\hline $\begin{array}{l}\text { Can Integrate Materials/ } \\
\text { Knowledge }\end{array}$ & 2.12 & 2.30 & 0.18 & 2.59 & 2.58 & -0.01 & 2.11 & 1.94 & -0.17 & 2.43 & 2.17 & -0.26 \\
\hline $\begin{array}{l}\text { Encouraged to Use } \\
\text { Activities to Evaluate }\end{array}$ & 2.24 & 2.40 & 0.16 & 2.63 & 2.70 & 0.07 & 2.29 & 2.22 & -0.07 & 2.57 & 2.34 & -0.23 \\
\hline Can Integrate & $4.12^{*}$ & $4.50^{*}$ & 0.38 & $5.14 *$ & $5.05^{*}$ & -0.09 & 4.37 & 4.43 & 0.06 & 4.74 & 4.43 & -0.31 \\
\hline $\begin{array}{l}\text { Encouraged to Use } \\
\text { Synthesis }\end{array}$ & 1.94 & 2.36 & 0.42 & 2.52 & 2.45 & -0.07 & 2.13 & 1.98 & -0.15 & 2.29 & 2.11 & -0.18 \\
\hline Can Use Synthesis & 2.16 & 2.29 & 0.13 & 2.45 & 2.49 & 0.04 & 2.13 & 1.96 & -0.17 & 2.34 & 2.37 & 0.03 \\
\hline
\end{tabular}

Note: * indicates a rating scale of 0-6 (6=higher ratings), all other ratings on a scale of 0-4 (4=higher ratings) 
Table 2. Paired Samples Test for Fluid Flow Operations

\begin{tabular}{|c|c|c|c|c|c|c|c|c|}
\hline \multirow{3}{*}{ Pre to Post Variable } & \multicolumn{5}{|c|}{ Paired Differences } & \multirow[b]{3}{*}{$\mathrm{t}$} & \multirow[b]{3}{*}{ df } & \multirow[b]{3}{*}{ Sig. (2-tailed) } \\
\hline & \multirow[b]{2}{*}{ Mean } & \multirow{2}{*}{\begin{tabular}{|l} 
Std. \\
Dev.
\end{tabular}} & \multirow{2}{*}{$\begin{array}{l}\text { Std. } \\
\text { Error } \\
\text { Mean } \\
\end{array}$} & \multicolumn{2}{|c|}{$\begin{array}{l}95 \% \\
\text { Confidence } \\
\text { Interval of the } \\
\text { Difference } \\
\end{array}$} & & & \\
\hline & & & & Lower & Upper & & & \\
\hline $\begin{array}{l}\text { Easily Presented } \\
\text { Furthered } \\
\text { Understanding }\end{array}$ & $\begin{array}{l}.74 \\
.47\end{array}$ & $\begin{array}{l}1.05 \\
1.03\end{array}$ & $\begin{array}{l}.20 \\
.16\end{array}$ & $\begin{array}{l}.42 \\
.15\end{array}$ & \begin{tabular}{|l|}
1.07 \\
.78
\end{tabular} & $\begin{array}{l}4.65 \\
2.96\end{array}$ & $\begin{array}{l}42 \\
42\end{array}$ & $\begin{array}{l}.000 \\
.005\end{array}$ \\
\hline
\end{tabular}


Table 3. Paired Samples Test for Heat Transfer Operations

\begin{tabular}{|c|c|c|c|c|c|c|c|c|}
\hline \multirow{3}{*}{$\begin{array}{l}\text { Pre to Post } \\
\text { Variable }\end{array}$} & \multicolumn{5}{|c|}{ Paired Differences } & \multirow[b]{3}{*}{$\mathrm{t}$} & \multirow[b]{3}{*}{$\mathrm{df}$} & \multirow{3}{*}{$\begin{array}{c}\text { Sig. } \\
\text { (2-tailed }\end{array}$} \\
\hline & \multirow[b]{2}{*}{ Mean } & \multirow{2}{*}{$\begin{array}{l}\text { Std. } \\
\text { Dev. }\end{array}$} & \multirow{2}{*}{$\begin{array}{l}\text { Std. Error } \\
\text { Difference }\end{array}$} & \multicolumn{2}{|c|}{$\begin{array}{l}\text { 95\% Confidence } \\
\text { Interval of the } \\
\text { Difference } \\
\end{array}$} & & & \\
\hline & & & & Lower & Upper & & & \\
\hline $\begin{array}{l}\text { Used Activities } \\
\text { to Illustrate }\end{array}$ & -1.32 & .84 & .14 & -1.62 & -1.03 & -9.16 & 33 & .000 \\
\hline $\begin{array}{l}\text { Furthered } \\
\text { Understanding }\end{array}$ & -.94 & 1.12 & 19 & -1.34 & -.54 & -4.83 & 33 & .000 \\
\hline $\begin{array}{l}\text { Encouraged to } \\
\text { Use Analysis }\end{array}$ & -.70 & 1.31 & .24 & -1.19 & -.21 & -2.91 & 29 & .007 \\
\hline $\begin{array}{l}\text { Can Use } \\
\text { Analysis }\end{array}$ & -.36 & .93 & .16 & -.69 & -.03 & -2.25 & 32 & .03 \\
\hline Can Be Flexible & -.38 & .78 & 13 & -.65 & -.11 & -2.86 & 33 & .007 \\
\hline
\end{tabular}


Table 4. Means With and Without Intensification in Chemical Reactor Design

\begin{tabular}{|l|c|c|c|}
\hline Variable & $\begin{array}{c}\text { Without } \\
\text { (fall 09) }\end{array}$ & $\begin{array}{c}\text { With } \\
\text { (fall 10) }\end{array}$ & Difference \\
\hline Easily Presented & 2.97 & 2.73 & .24 \\
\hline Used Activities to Illustrate & 2.33 & 1.90 & .43 \\
\hline $\begin{array}{l}\text { Encouraged to Use } \\
\text { Flexibility }\end{array}$ & 2.88 & 2.78 & .10 \\
\hline Furthered Understanding & 2.52 & 2.20 & .32 \\
\hline Can Problem Solve & 2.82 & 2.60 & .22 \\
\hline Can Be Flexible & 2.75 & 2.45 & .30 \\
\hline $\begin{array}{l}\text { Can Integrate } \\
\text { Materials/Knowledge }\end{array}$ & 2.55 & 2.65 & -.10 \\
\hline Encouraged to Use Analysis & 5.22 & 4.93 & .29 \\
\hline $\begin{array}{l}\text { Encouraged to Integrate } \\
\text { Materials/Knowledge }\end{array}$ & 2.67 & 2.53 & .14 \\
\hline $\begin{array}{l}\text { Encouraged to Problem } \\
\text { Solve }\end{array}$ & 2.88 & 2.78 & .10 \\
\hline Able to Integrate & 5.22 & 4.93 & .29 \\
\hline Encouraged to Use Synthesis & 2.70 & 2.50 & .20 \\
\hline Can Use Synthesis & 2.49 & 2.50 & -.010 \\
\hline
\end{tabular}


Table 5. Independent Samples Test for Chemical Reactor Design

\begin{tabular}{|c|c|c|c|c|c|c|c|}
\hline \multirow{3}{*}{ Pre to Post Variable } & \multicolumn{4}{|c|}{ Differences } & $\mathrm{t}$ & $\mathrm{df}$ & $\begin{array}{c}\text { Sig. } \\
\text { (2-tailed) }\end{array}$ \\
\hline & \multirow[b]{2}{*}{ Mean } & \multirow{2}{*}{$\begin{array}{l}\text { Std. } \\
\text { Dev. }\end{array}$} & \multicolumn{2}{|c|}{$\begin{array}{l}\text { 95\% Confidence } \\
\text { Interval of the } \\
\text { Difference }\end{array}$} & & & \\
\hline & & & Lower & Upper & & & \\
\hline Easily Presented & .24 & .84 & .04 & .44 & 2.44 & 71 & .02 \\
\hline $\begin{array}{l}\text { Used Activities to } \\
\text { Illustrate }\end{array}$ & .40 & 1.12 & .04 & .77 & 2.21 & 71 & .03 \\
\hline Can Be Flexible & .03 & 1.31 & .04 & .56 & 2.26 & 71 & .03 \\
\hline Can Problem Solve & .06 & .78 & .01 & .44 & 1.92 & 70 & .06 \\
\hline
\end{tabular}


Table 6. Comparison of Pre and Post-Survey on Simulated Moving Bed Reactor Module

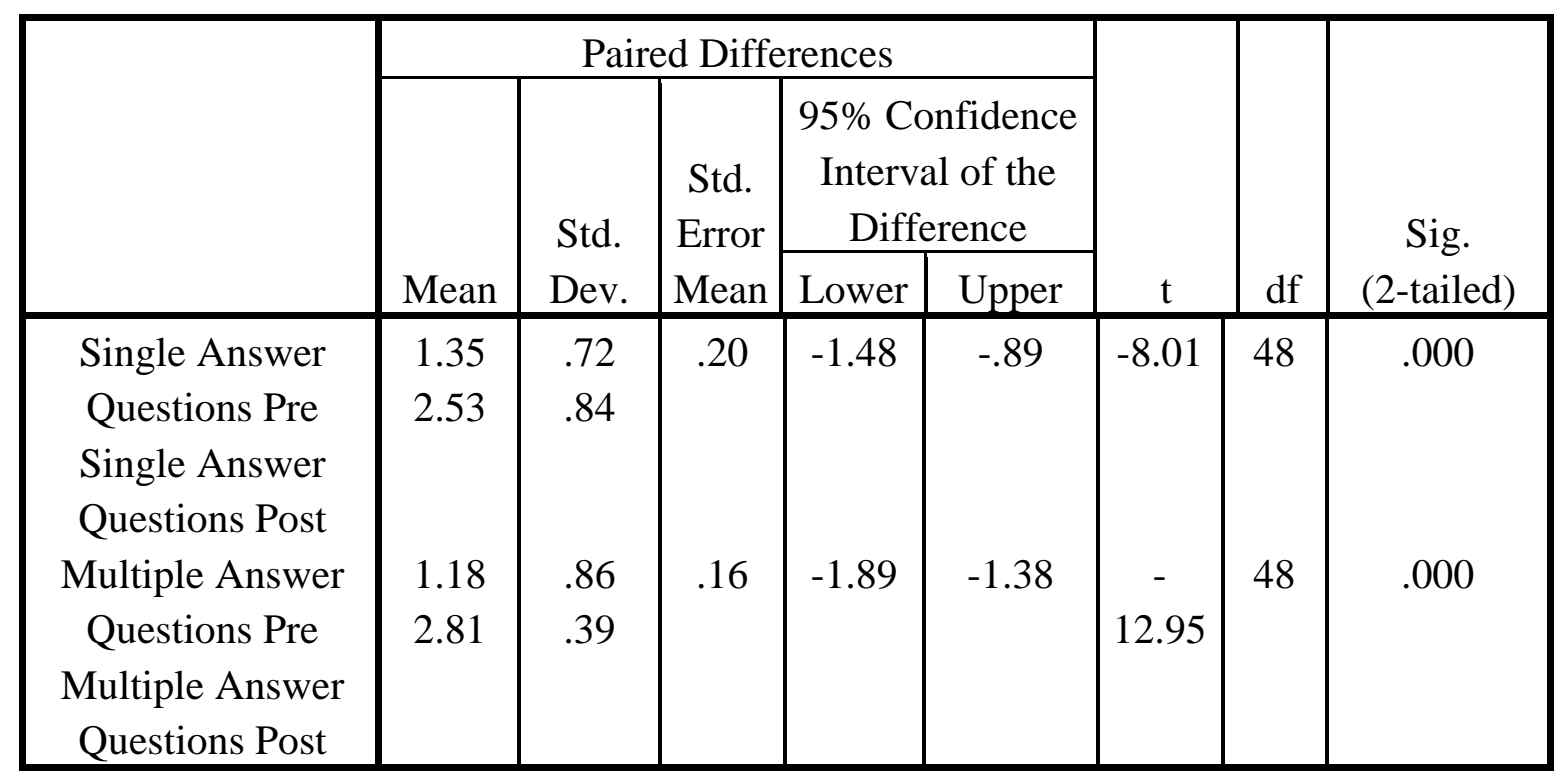

